\title{
Lowering forest habitat does not reduce forage availability to the eastern honey bees in summer and fall
}

\author{
Feng $\mathrm{LIU}^{1,2}$, Ge ZHANG ${ }^{3}$, Jiamin QIN ${ }^{1,4}$, Wujun $\mathrm{JIANG}^{1}$, Qun Luo ${ }^{1}$, Xijian Xu ${ }^{1}$, \\ Fanggui $\mathrm{XI}^{1}$, Fang $\mathrm{YUAN}^{1}$, Zuolin $\mathrm{YI}^{1}$, Hongxia $\mathrm{HE}^{1}$, Wuguang $\mathrm{YE}^{1}$, Pingli DAI \\ ${ }^{1}$ Apiculture Institute of Jiangxi Province, Nanchang 330052, People's Republic of China \\ ${ }^{2}$ Key Laboratory of Pollinating Insect Biology, Institute of Apicultural Research, Chinese Academy of Agricultural \\ Sciences, Beijing 100093, People's Republic of China \\ ${ }^{3}$ Department of Entomology, Iowa State University, Ames, IA 50010, USA \\ ${ }^{4}$ Yunnan Academy of Agricultural Sciences, Institute of Sericultural and Apiculture, Mengzi, Yunan 661101, People's \\ Republic of China
}

Received 11 June 2019 - Revised 12 December 2019 - Accepted 6 February 2020

\begin{abstract}
The eastern honey bee (Apis cerana) is an important managed pollinator adapted to forest landscapes in China and other Asian countries adjacent to China. Eastern honey bee is thought to be threatened by forage deficiency due to deforestation; however, limited research is available to support this assumption. Our study will determine whether varying subtropical forests, the major shelter of eastern honey bees in China, affects bee forage and health. We placed hives at locations with high (HFC), medium (MFC), or low forest cover (control) and monitored the forage collection and bee population in the summer and fall. We found that available forage and bee population size (including larvae, capped pupae, and adult bees) were not significantly different among control, MFC, and HFC. Forage and larvae and pupae amount under control and MFC tended to be more abundant and larger compared with HFC. Though forage was not reduced by low forest cover, eastern honey bees at the control locations died potentially due to disease transmission and pesticide use in adjacent crops as well as vandalism. This study suggested the medium forest cover may be a compromise strategy to insure the forage availability and buffer colonies from environmental stress. Further study needs to confirm the application of this strategy.
\end{abstract}

\section{forested landscape / subtropical forest / Apis cerana / pollen / honey}

\section{INTRODUCTION}

Eastern honey bee (Apis cerana) is native honey bee species adapted to a diverse array of forested habitats (from tropical to temperate) in

Electronic supplementary material The online version of this article (https://doi.org/10.1007/s13592-020-00746-5) contains supplementary material, which is available to authorized users.

Corresponding author: W. Ye, 851592486@qq.com;

P. Dai, daipingli@ caas.cn

Feng Liu and Ge Zhang contributed equally to this work.

Manuscript editor: James Nieh
China and other countries in the Far East (Peng et al. 1989; Pokhrel et al. 2006). Among 11 provinces in the southern part of China (south to Yangtze River, accounting for nearly one fourth of the country) that are partially or wholly in the subtropical zone, 7 have $>50 \%$ forest cover, where a subspecies of eastern honey bees (Apis cerana cerana) mainly survives. As a domesticated pollinator species, eastern honey bees have high economic and ecological value, but their population are declining due to fierce forage competition and disease transmission from western honey bees (Apis mellifera) in addition to parasites and pesticides (Hepburn and Radloff 2011). Forage deficiency due to deforestation is another 
widely accepted cause for the decline of eastern honey bees in China. However, scientific research on how deforestation affects the forage collection and health of eastern honey bees in forests is lacking. In contrast with forests, other land uses such as agricultural lands contributing to deforestation can provide abundant forage to honey bees when open areas within those land uses such as field edges, roadside, and fallow land support flowering forbs or shrubs for bee forage (Requier et al. 2015; Sponsler and Johnson 2015; Colwell et al. 2017). As generalist foragers, eastern honey bees may take advantages of forage in land uses other than forests and be less likely to fail after deforestation.

Temperate forests are attracting forage habitats to both western honey bees (Gaines-Day and Gratton 2016) and eastern honey bees (Hill and Webster 1995; Youn 2009). In temperate forests during spring, different forest cover affects western honey bee forage behavior when colonies are placed in orchards for pollination (Gaines-Day and Gratton 2016). The western honey bees were distracted to flowering forest under high forest cover, ignoring the orchard. Temperate forests can promote nectar collection for eastern honey bees in spring (Hill and Webster 1995; Youn 2009). In the tropical forest during the dry season, the closer the western honey bee colonies are to the blooming forest, the higher honey yield will be (Sande et al. 2009). As an ecosystem different from temperate and tropical forests, whether subtropical forests provide abundant forage to eastern honey bees is unknown. Under natural condition, eastern honey bees depend on subtropical forests for nest place, but it does not mean subtropical forests always provide sufficient forage to honey bees. As eastern honey bees are hosted by manmade hive boxes, they may have the capability to disentangle the dependence on forests if floral resource in other land uses is accessible to them.

A lack of forage availability may occur to bee colonies managed in the forests after the tree blooming period has ended, but amount of flowers from forbs and shrubs is suppressed in forests. In the early summer of temperate and subtropical forests, the canopy of the forests is closing along with growing leaves. The plant populations of the understory layer are suppressed due to scarce light reaching to them, and only a few shade-tolerant shrubs and forbs survive (Li et al. 1999; McKenzie et al. 2000). Even if the shrub and forb layer can flower under the canopy, the number of flowers of the individual surviving plants is limited (Bierzychudek 1982; McKenzie et al. 2000; Kudo et al. 2008). When most forest trees cease blooming, honey bees may hardly find enough forage in the forested habitat (Chang-Yang et al. 2013; Lin et al. 2003; Liu et al. 2003; Mensah et al. 2017; Shukla and Ramakrishnan 1982). Winfree et al. (2007) demonstrated that wild bee abundance and species richness decline with increasing forest cover in forested landscapes, suggesting that forest may not provide sufficient forage.

By choosing a critical period, i.e., postblooming of trees, we studied whether decreasing forest cover affected the forage collection and health of eastern honey bees in the subtropical forests. We hypothesized that medium forest cover (MFC) with moderate agricultural development or low forest cover with high agricultural development (control) would not affect the forage and health of eastern honey bees compared with high forest cover (HFC), when agricultural lands as the major disturbing land uses have open areas for flourish of flowering forbs and shrubs.

\section{METHODS}

\subsection{Research area}

Nine locations were found for installing eastern honey bee colonies in Yichun and Nanchang cities of Jiangxi province, China (Figure 1; Appendix Table 3). Six locations located in Yifeng County in Yichun city with forest as the dominant land uses were grouped into two categories based on their forest cover, i.e., high forest cover (HFC) and medium forest cover (MFC) (Table I). Three control locations were found in an agricultural landscape with cropland and urban as the major land use in Nanchang (Table I). The forest cover was measured by ArcMap 10.5 (Eris, Redlands, USA) based on the $30 \times 30 \mathrm{~m}$ land cover map made by Tsinghua University. Each location was at least $3.2 \mathrm{~km}$ apart from each other. The subtropical forest of the research area was a mix of coniferous 

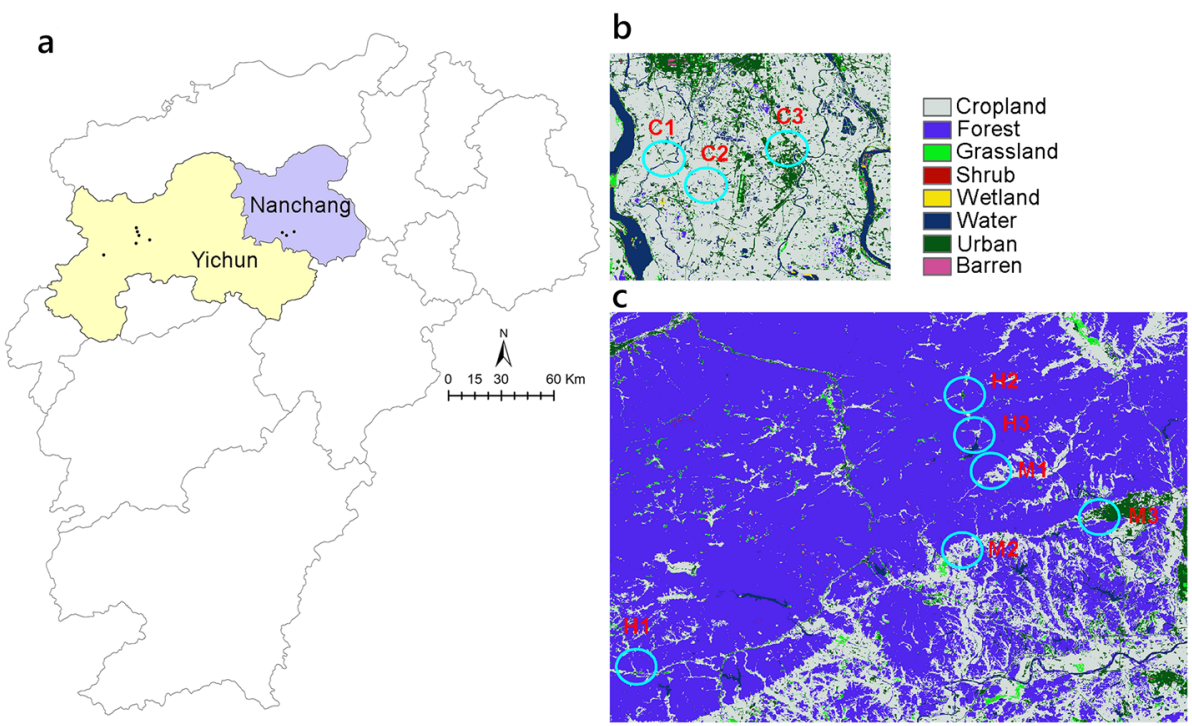

Figure 1. The locations of research apiaries in Jiangxi province (a) and landscape compositions of surrounding landscape areas around apiaries within $1.6 \mathrm{~km}$ radius $(\mathbf{b}, \mathbf{c})$. The black dots in the territory of Nachang and Yichun cities represent the locations of apiaries (a). Three control locations with low forest cover (C1-3) were in Nanchang City (b), and three locations of MFC (M1-3) or HFC (H1-3) were in Yichun city (c).

and deciduous broadleaved trees. The conifers mainly included Cunninghamia lanceolata (China fir), Pinus massoniana (Chinese red pine), and Pinus elliottii (slash pine), while, the broadleaved evergreen trees included Alniphyllum fortunei,
Canarium album (Chinese white olive), Liquidambar formosana (Chinese sweet gum), Sapium discolor (mountain tallow), and Schima superba . Coniferous trees are not major sources of forage for eastern honey bees, but broadleaved evergreen

Table I. Percentage of forest and other land use of the landscape surrounding each location (apiary) within the radius of $1.6 \mathrm{~km}$

\begin{tabular}{|c|c|c|c|c|c|}
\hline \multirow{2}{*}{$\begin{array}{l}\text { Forest cover } \\
\text { category }\end{array}$} & \multirow{2}{*}{$\begin{array}{l}\text { Location (apiary) } \\
\text { ID }\end{array}$} & \multicolumn{4}{|c|}{$\%$ of forest and other land uses } \\
\hline & & Forest & $\begin{array}{l}\text { Cropland and } \\
\text { urban }\end{array}$ & $\begin{array}{l}\text { Grassland and } \\
\text { shrub }\end{array}$ & $\begin{array}{l}\text { Wetland and } \\
\text { water }\end{array}$ \\
\hline \multirow[t]{3}{*}{ Control (low) } & $\mathrm{C} 1$ & 0 & 93.59 & 0.80 & 5.61 \\
\hline & $\mathrm{C} 2$ & 0.27 & 94.11 & 0.80 & 4.82 \\
\hline & $\mathrm{C} 3$ & 0.40 & 94.39 & 1.87 & 3.34 \\
\hline \multirow[t]{3}{*}{ Medium (MFC) } & M1 & $75.43^{\mathrm{a}}$ & 23.63 & 0.80 & 0.13 \\
\hline & M2 & 50.53 & 45.99 & 2.81 & 0.67 \\
\hline & M3 & 49.27 & 46.60 & 1.20 & 2.94 \\
\hline \multirow[t]{3}{*}{ High (HFC) } & H1 & 92.91 & 5.75 & 1.34 & 0.00 \\
\hline & $\mathrm{H} 2$ & 86.76 & 6.55 & 1.34 & 5.35 \\
\hline & $\mathrm{H} 3$ & 87.17 & 10.83 & 2.01 & 0 \\
\hline
\end{tabular}

\footnotetext{
${ }^{\text {a }}$ Apiary in location M1 was next to a big patch of cropland (Figure 1) that accounted for the most part of its surrounding landscape, and we designate this location as a medium forest cover
} 
trees are. Sapium discolor, blooming in May and June, was the most important forage resource for the eastern honey bees in the subtropical forest of the study area, from which a colony could usually collected 15 to $50 \mathrm{~kg}$ honey (reported by local beekeepers). The high content of alkaloids (toxic to insects) in $S$. superba reduces its value as forage to bees. L. formosana, C. album, and A. fortunei flower in April and May and are minor forage sources for eastern honey bees. Rice as the dominant crop in our study area was one of pollen source to eastern honey bees.

\subsection{Apiary management and hive inspection}

An apiary of two eastern honey bee colonies (Apis cerana cerana Fabricius) was installed at each location selected for this research. Each colony kept in standard Langstroth bee hives was attached with an entrance pollen trap for trapping pollen from corbicula. The colonies started with similar amounts of bees and food storage and were placed out into study locations on the $21 \mathrm{st}$ of July 2017. The colonies were inspected every other week to estimate colony weight, hive-stored pollen, unsealed (larvae) and sealed (pupae) brood, and adult bees. Once the nectar was brought back to hive boxes, it will be condensed to honey. We used the colony weight to indicate the nectar forage as majority of a colony weight is composed by honey. We used the hive-stored pollen and trapped pollen to determine if the pollen forage differed among varying forest cover. The hive-stored pollen is an accumulative pollen storage of surplus pollen after consumption (Fewell and Winston 1992). However, the trapped pollen reflects the abundance of pollen of a single day, i.e., the time when the pollen trap was opened. Populations of unsealed and sealed brood and adult bee were measured to assess the health of the colonies (Todd and Reed 1970). Unsealed and sealed brood were estimated by a transparent plastic plate being the same size of a frame that was divided into 196 equal blocks. The adult bee population was visually estimated by two inspectors every time. Amount of adult honey bees fully covering one side of a frame without overlapping bees was defined as one frame side of bees. No food supplement was given to any research colonies. Miticide for varroa mite (Varroa destructor) control was not applied since eastern honey bees are resistant to varroa mite infestation. All the hives retained the queen during the experimental period.

\subsection{Pollen collection and identification}

We opened the hive entrance pollen trap on the day of hive inspection and collected the pollen on the following day. The trapped pollen per hive per date was weighed and stored at $-20{ }^{\circ} \mathrm{C}$ before analysis. Pollen collected during $24 \mathrm{~h}$ from the two colonies at each site was pooled, and $2 \mathrm{~g}$ of pollen were extracted from the pooled pollen for counting number of different pollen types. The $2 \mathrm{~g}$ of pollen were sorted by color and dissolved in Calberla's fluid (Weber 1998) and then mounted to microscopic glass slides. The pollen diversity was assessed by number of pollen types in the $2 \mathrm{~g}$ of pollen.

\subsection{Colony mortality monitor}

Mortality of bee hives across different forest cover was recorded in this study. No sample from those dead colonies was analyzed for determining the pesticides or pathogens that may be the cause of mortality. However, we tracked the pesticide application by contacting farmers farming nearby our bee hives when tracking colony mortality. During each field work, we also checked disease symptom that can be visually judged.

\subsection{Statistics}

We used repeated measures ANOVA to determine the effects of differing forest cover on forage collection, brood, and adult bee populations. The analysis results were obtained using Proc Mixed SAS 9.3 software (SAS Institute, Cary, NC). The apiary average of nectar weight, hive-stored pollen area, trapped pollen weight, pollen diversity, and unsealed and sealed brood area were 
dependent variables and forest cover was the independent variable. We used differences of least square means to compare the significant difference of those parameters between the differing forage cover on each individual day.

\section{RESULTS}

\subsection{Nectar forage}

The amount of nectar collected by eastern honey bees was not significantly different among different forest covers $(p>0.05)$ (Table II; Figure 2), so did not the nectar collected on individual date $(p>0.05)$. Nectar forage under HFC was declining from the start to the end of the experiments. In contrast, nectar forage under MFC and control can keep steady until middle October, near the end of the experiment.

\subsection{Pollen forage}

We did not find a significant difference in the abundance of hive-stored and trapped pollen among forest cover $(p>0.05)$ (Table II; Figure 3$)$. The pollen diversity did not differ between HFC and MFC $(p>0.05)$ (Table II; Figure 3), and the honey bees collected less than two pollen types every day.

\subsection{Brood and adult bee population}

The populations of brood, including unsealed brood (larvae) and sealed brood (pupae), and adult bees did not significantly differ among the various forest cover types $(p>0.05)$ (Table II; Figure 4). On 6 of 7 days, the populations of the unsealed and sealed brood under MFC were more than that of HFC. The unsealed brood of the control were more than that of MFC and HFC. The unsealed and sealed brood declined at all of the sites at the end of the experiments. The populations of adult bees under MFC were consistently similar to or higher than that under HFC (Table II; Figure 5) but not significantly different. The populations of adult bees under the control fluctuated intensively compared with that under HFC and MFC.

\subsection{Colony mortality}

All of the colonies at the control sites died due to different reasons before the end of the experiment (Figure 2). All colonies at one control site were infected with European foul brood. The colonies at the second control site were correlated to poisoning by insecticides that were observed to be sprayed near our apiary location. The colonies at the third control were knocked down by a group of teenagers. One colony under MFC died with undetermined reasons prior to the last colony inspection. All colonies under HFC survived to the end of the experiment.

\section{DISCUSSION}

The nectar collected by the eastern honey bees was not significantly different among the varying forest cover, suggesting that decreasing forest

Table II. Repeat measures ANOVA for comparing different parameters among different forest cover

\begin{tabular}{llcc}
\hline Parameter & Degree of freedom & $F$ value & $P$ value \\
\hline Colony weight & $2,5.98$ & 0.97 & 0.4308 \\
Stored pollen & $2,5.94$ & 1.00 & 0.4209 \\
Trapped pollen & 1,4 & 1.67 & 0.2665 \\
Pollen diversity & 1,17 & 2.14 & 0.1617 \\
Unsealed brood & 2,6 & 1.74 & 0.2542 \\
Sealed brood & $2,6.1$ & 0.73 & 0.5203 \\
Adult bee & $2,6.02$ & 0.15 & 0.8603 \\
\hline
\end{tabular}




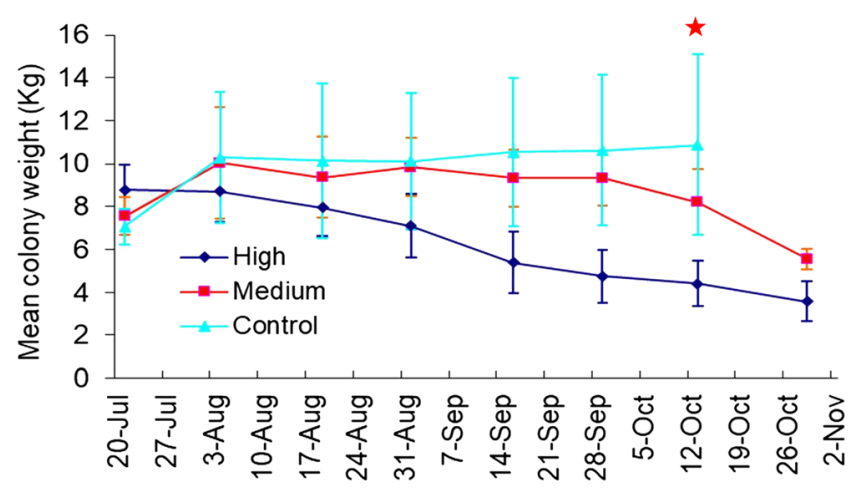

Figure 2. The colony weight under the three different forest cover over time. The colony weight did not significantly differ among the varying forest cover generally (Table II). On each day, the colony weight did not significantly differ based on analysis by the differences of least square mean ( $p>0.05$ for all dates). The red five-pointed star on the graph indicated the time point when all the colonies died in all control locations. And the following Figures 3, 4, and 5 also did not show any information on pollen, brood, and adult bee population for controls once after the colony death.

cover did not reduce nectar forage for the honey bees. Although the nectar secretion of wild flowers is thought to decrease overall in fall (Beutler 1953; USDA 2016), the colonies under MFC and the control retained their colony weights until the end of fall in our study. However, the colonies under HFC lost weight throughout the entire experiment period, suggesting a lack of nectar forage for honey bees under HFC after the trees ceased bloom. MFC and control with moderate or high agricultural development seemed to improve nectar collection in contrast with HFC (Figure 2) but not at a statistical significant level. Agricultural land adjacent to the forests was rich in flowering forbs (Requier et al. 2015; Sponsler and Johnson 2015; Colwell et al. 2017) that can be foraged by honey bees for nectar in summer and fall. A case found in North America was that forbs such as goldenrod in agricultural lands can produce abundant nectar to mitigate nectar forage dearth in fall (Ginsberg 1983; USDA 2016). Rice, as a wind-pollinated dominant crop in our study area did not provide valuable nectar to eastern honey bees.

The abundance of both hive-stored and trapped pollen did not significantly differ among different forest cover, suggesting that decreasing forest cover did not reduce the pollen forage for the honey bees. The pollen abundance under MFC and the control tended to be generally greater than that under HFC, which may be led by abundant forbs and shrubs in open areas of agricultural land. Previous study demonstrated that with flowering forbs in the uncultivated open areas, agricultural lands can offer relatively abundant and diverse pollen for honey bees in later seasons (Requier et al. 2015). In addition, rice contributed to pollen availability to eastern honey bees. Both the stored and trapped pollen under HFC increased for a short period in early August but declined after middle August. In contrast, stored and trapped pollen under MFC experienced a continuous increase from July to later September, a trend that was also found in a previous study (Roubik 1982). The pollen diversity of both MFC and HFC was low, indicating low floral diversity in the subtropical forest of the study area regardless of how the forest cover varied.

The lack of significant differences in brood (including unsealed and sealed brood) between MFC and HFC indicated that reducing the forest cover did not affect the brood production in eastern honey bees. The pollen is mainly used by nurse bees to brood larvae, and the low availability of pollen cannot support good brood production (Schmickl and Crailsheim 2001, 2002; Mattila and Otis 2007). We did not find a significant difference in pollen collection among the different forest cover, so it was reasonable to find an insignificant 

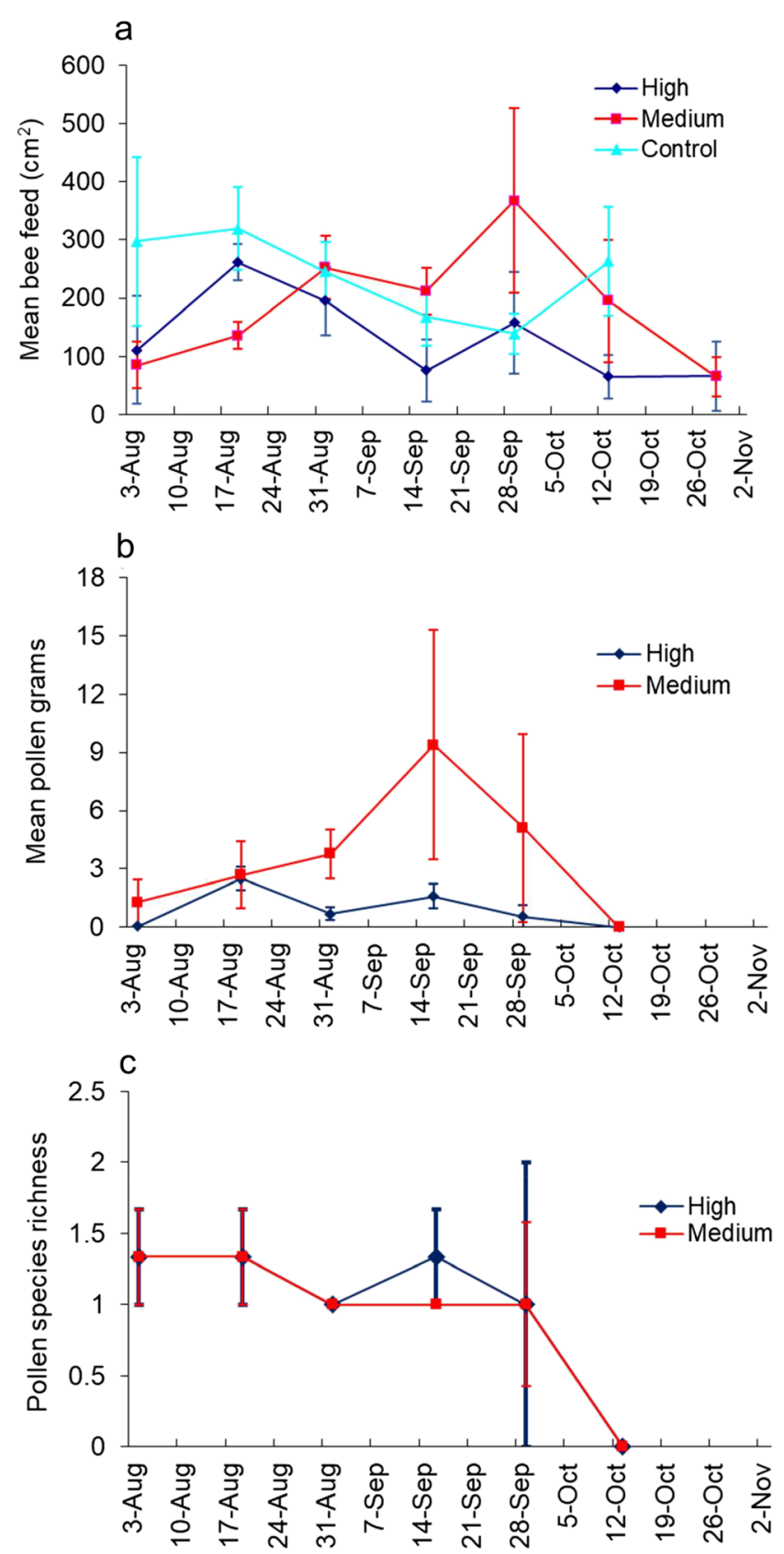

Figure 3. Abundance of hive-stored pollen (a) and trapped pollen (b) and pollen diversity of trapped pollen (c) across the entire course of the experiment. Pollen abundance and pollen diversity did not significantly differ among the varying forest cover (Table II). On each day, the pollen abundance or diversity also did not significantly differ based on analysis by difference of least square mean $(p>0.05)$.

difference in brood production. However, MFC tended to a greater population than HFC. The amount of unsealed brood under the control was generally greater than that of MFC and HFC, but some of them may not survive to the period of sealed brood when 

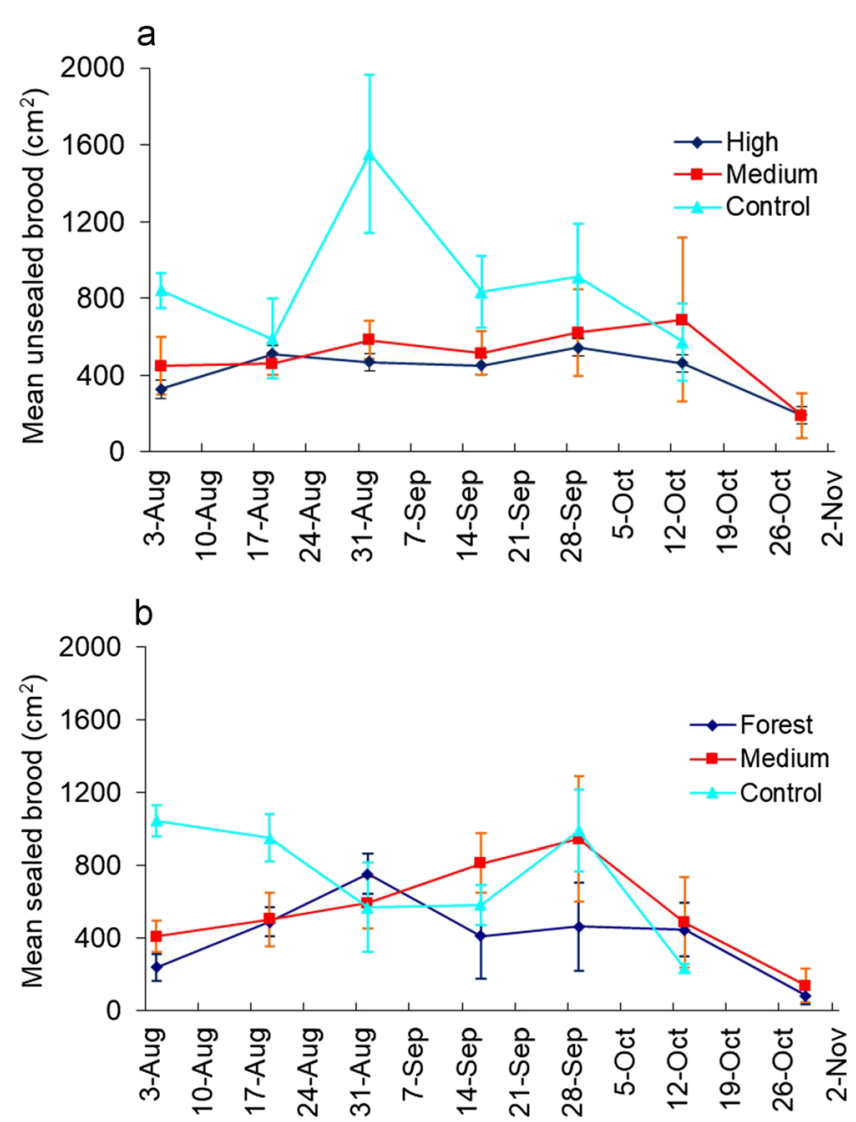

Figure 4. The amount of unsealed brood (a) and sealed brood (b) across the entire course of the experiment. The brood did not significantly differ among the varying forest cover (Table II). On each day, the pollen abundance or diversity also did not significantly differ based on analysis by difference of least square mean $(p>0.05)$.

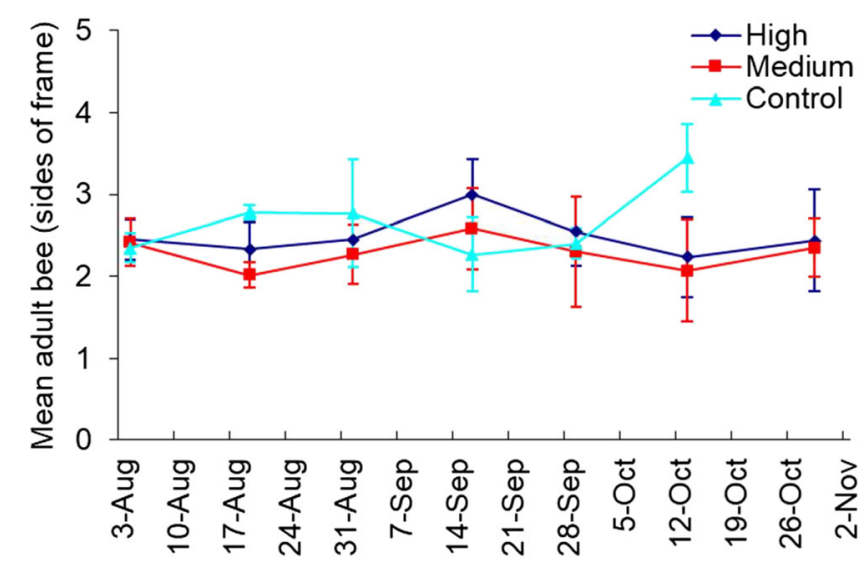

Figure 5. Population of adult bees across the entire course of the experiments. Adult bees did not significantly differ among the varying forest covers (Table II). On each day, the pollen abundance or diversity also did not significantly differ based on analysis by difference of least square mean $(p>0.05)$. 
sealed brood did not increase after the peak of unsealed brood. The end of October met a simultaneously brood decline under HFC, MFC, and control coinciding with plant senescence due to decreasing temperature and photoperiod. Because of fewer forage options available under $\mathrm{HFC}$, more foragers may stay in hive, resulting in larger adult bee populations under HFC compared with that under MFC. The adult bee population under the control was fluctuating and less predictable.

Evidence from former studies on wild bees (summed in Appendix Table 4) seems to support our thought that pollen and nectar forage tended to be enhanced in locations with MFC compared with those with HFC. Open areas created in a forest, including small-scaled farming and logging, early succession, fire disturbance, and forest edges, enhance the diversity of the understory forbs and shrubs, thus providing more floral resources to the bees. However, a limited open area of dense or mature forest suppressed the growth and flowering of forbs and shrubs, providing less forage to bees (summed in Appendix Table 5). Continuous loss and fragmentation of forest habitats in agricultural matrices challenge the survival of wild bees because they may require undisturbed forests as nesting places and particular flowers in forest. In contrast, without the need for nesting locations, honey bees as a generalist foragers are more resistant to severe forest disturbances and may even benefit from forest disturbances after more open habitat is exposed.

Eastern honey bees may benefit from forage in agricultural land in proximity to the forests, but may be possibly endangered by pesticide, disease transmission and unpredictable vandalism. Pesticide sprayed in surrounding croplands during crop flowering period may be a source of poisoning to honey bees. In Jiangxi province, western honey bees are more frequently kept at flat land where agriculture develops, which can increase the probability of inter-species disease transmission. European foul brood may be transmitted from western honey bees to eastern honey bees when those two species share same forage resource. Under a severe case, western honey bees can rob eastern honey bee colonies to transmit disease by direct contact. The risk of vandalism is another unpredictable issue for keeping bees in agricultural land with a large population, and many reports have demonstrated purposely damage to bee colonies around world. However, it is not an increasing concern when importance of honey bees is realized by the public.

In conclusion, lower forest cover with intensive agricultural development may challenge eastern honey bees by pesticide and pathogens. In contrast, high forest cover induced a trend of forage shortage. It seems that keeping eastern honey bees in a forest landscape with moderate disturbance in summer and fall in a subtropical forest is a compromised strategy to provide reliable forage and avoid pesticides and pathogens. At the same time, beekeepers, farmers, and forest managers need to cooperate to avoid the poisoning incidence of bees caused by insecticide applications around bee hives. Keeping a long distance between western honey bees and eastern honey bee apiaries may be a potential approach to reduce forage competition and disease transmission. Further large-scale experiments are necessary to confirm our findings.

\section{ACKNOWLEDGMENTS}

We appreciate the help from Chuanlian Zhang, Wen Lou, Yongping Jiang, and Qun Tu for managing bees and collecting data and pollen samples. We also appreciate the beekeepers and farmers, Jieping Jin, Chao Li, and Chichang Yang, who provided apiary locations and protected bee hives from natural or anthropological interference. Thanks to the funding from Key Laboratory of Pollinating Insect Biology, Ministry of Agriculture and Rural Affairs, China.

\section{AUTHOR CONTRIBUTIONS}

LF, ZG, DP, and YW conceived this research and designed experiments. LF, ZG, QJ, JW, LQ, XX, $\mathrm{XF}, \mathrm{YF}$, and $\mathrm{YZ}$ performed experiments and analysis. LF and $Z G$ participated in the design and interpretation of the data. $\mathrm{LF}, \mathrm{ZG}$, and YW wrote the paper and participated in the revisions of it. All authors read and approved the final manuscript. 


\section{COMPLIANCE WITH ETHICAL STANDARDS}

Conflict of interest The authors declare that they have no conflict of interest.

La réduction des habitats forestiers en été et en automne ne réduit pas la disponibilité des sources de nourriture pour l'abeille de l'Est.

Paysage forestier / Forêt subtropicale / Apis cerana / Pollen / Miel.

Die Verringerung von Waldhabitaten im Sommer und Herbst reduziert nicht die Verfügbarkeit von Futterquellen für die Östliche Honigbiene.

Waldlanschaften / subtropischer Wald / Apis cerana / Pollen / Honig.

\section{REFERENCES}

Beutler R. (1953) Nectar. Bee World 34 (6), 106-116. https://doi.org/10.1080/0005772X.1953.11094798

Bierzychudek P. (1982) Life histories and demography of shade-tolerant temperate forest herbs: a review. New Phytol. 90 (4), 757-776. https://doi.org/10.1111 /j.1469-8137.1982.tb03285.x

Chang-Yang C.H., Lu C.L., Sun I.F., Hsieh C.F. (2013) Flowering and fruiting patterns in a subtropical rain forest, Taiwan. Biotropica 45 (2), 165-174. https://doi. org/10.1111/j.1744-7429.2012.00911.x

Colwell M.J., Williams G.R., Evans R.C., Shutler D. (2017) Honey bee- collected pollen in agroecosystems reveals diet diversity, diet quality, and pesticide exposure. Ecol. Evol. 7 (18), 7243-7253. https://doi.org/10.1002/ece3.3178

Fewell J.H., Winston M.L. (1992) Colony state and regulation of pollen foraging in the honey bee, Apis mellifera L. Behav. Ecol. Sociobil. 30 (6), 387-393. https://doi.org/10.1007/BF00176173

Gaines-Day H.R., Gratton C. (2016) Crop yield is correlated with honey bee hive density but not in highwoodland landscapes. Agric. Ecosyst. Environ. 218, 53-57. https://doi.org/10.1016/j.agee.2015.11.001

Ginsberg H.S. (1983) Foraging ecology of bees in an old field. Ecology 64 (1), 165-175. https://doi.org/10.2307 $/ 1937338$

Hepburn H.R., Radloff S.E. (2011) Honeybees of Asia. Springer-Verlag, Berlin, Germany. https://doi. org/10.1007/978-3-642-16422-4
Hill D.B., Webster T.C. (1995) Apiculture and forestry (bees and trees). Agroforest Syst. 29 (3), 313-320. https://doi.org/10.1007/BF00704877

Kudo G., Ida T.Y., Tani T. (2008) Linkages between phenology, pollination, photosynthesis, and reproduction in deciduous forest understory plants. Ecology 89 (2), 321-331. https://doi.org/10.1890/06-2131.1

Li X., Wilson S.D., Song Y. (1999) Secondary succession in two subtropical forests. Plant Ecol. 143 (1), 13-21. https://doi.org/10.1023/A:100980651

Lin K.C., Hamburg S.P., Tang S.L., Hsia Y.J., Lin T.C. (2003) Typhoon effects on litterfall in a subtropical forest. Can. J. For. Res. 33 (11), 2184-2192. https://doi.org/10.1139/x03-154

Liu W., Fox J.E., Xu Z. (2003) Litterfall and nutrient dynamics in a montane moist evergreen broad-leaved forest in Ailao Mountains, SW China. Plant Ecol. 164 (2), 157-170. https://doi.org/10.1023 /A:102120101

Mattila H.R., Otis G.W. (2007) Dwindling pollen resources trigger the transition to broodless populations of longlived honeybees each autumn. Ecol. Entomol. 32 (5), 496-505. https://doi.org/10.1111/j.13652311.2007.00904.x

McKenzie D., Halpern C.B., Nelson C.R. (2000) Overstory influences on herb and shrub communities in mature forests of western Washington, USA. Can. J. For. Res. 30 (10), 1655-1666. https://doi.org/10.1139/x00-091

Mensah S., Veldtman R., Seifert T. (2017) Potential supply of floral resources to managed honey bees in natural mistbelt forests. J. Environ. Manage. 189, 160-167. https://doi.org/10.1016/j.jenvman.2016.12.033

Peng Y.S., Nasr M.E., Locke S.J. (1989) Geographical races of Apis cerana Fabricius in China and their distribution. Review of recent Chinese publications and a preliminary statistical analysis. Apidologie 20 (1), 9-20. https://doi.org/10.1051/apido:19890102

Pokhrel S., Thapa R.B., Neupane F.P., Shrestha S.M. (2006) Absconding behavior and management of Apis cerana F. honeybee in Chitwan, Nepal. J. Inst. Agric. Anim. Sci. 27, 77-86. https://doi.org/10.3126/jiaas. v27i0.699

Requier F., Odoux J.F., Tamic T., Moreau N., Henry M., Decourtye A., Bretagnolle V. (2015) Honey bee diet in intensive farmland habitats reveals an unexpectedly high flower richness and a major role of weeds. Ecol. Appl. 25 (4), 881-890. https://doi.org/10.1890/141011.1

Roubik D.W. (1982) Seasonality in colony food storage, brood production and adult survivorship: studies of Melipona in tropical forest (Hymenoptera: Apidae). J. Kans. Entomol. Soc. 55 (4), 789-800

Sande S.O., Crewe R.M., Raina S.K., Nicolson S.W., Gordon I. (2009) Proximity to a forest leads to higher honey yield: another reason to conserve. Biol. Conserv. 142 (11), 2703-2709. https://doi.org/10.1016/j. biocon.2009.06.023

Schmickl T., Crailsheim K. (2001) Cannibalism and early capping: strategy of honeybee colonies in times of 
experimental pollen shortages. J. Comp. Physiol. A 187 (7), 541-547. https://doi.org/10.1007 /s003590100226

Schmickl T., Crailsheim K. (2002) How honeybees (Apis mellifera L.) change their broodcare behaviour in response to non-foraging conditions and poor pollen conditions. Behav. Ecol. Sociobiol. 51 (5), 415-425. https://doi.org/10.1007/s00265-002-0457-3

Shukla R.P., Ramakrishnan P.S. (1982) Phenology of trees in a sub-tropical humid forest in North-Eastern India. Vegetatio 49(2), 103-109. https://doi.org/10.1007 /BF00052764

Sponsler D.B., Johnson R.M. (2015) Honey bee success predicted by landscape composition in Ohio, USA. PeerJ 3, e838. https://doi.org/10.7717/peerj.838

Todd F.E., Reed C.B. (1970) Brood measurement as a valid index to the value of honey bees as pollinators. J. Econ. Entomol. 63 (1), 148-149. https://doi.org/10.1093 /jee/63.1.148
USDA (2016) National Honey Report. https://www.ams. usda.gov/mnreports/fvmhoney.pdf. Accessed 22 Jan 2019

Weber R.W. (1998) Pollen identification. Ann. Allergy Asthma. Immunol. 80 (2), 141-148. https://doi. org/10.1016/S1081-1206(10)62947-X

Winfree R., Griswold T., Kremen C. (2007) Effect of human disturbance on bee communities in a forested ecosystem. Conserv. Biol. 21 (1), 213-223. https://doi. org/10.1111/j.1523-1739.2006.00574.x

Youn Y.C. (2009) Use of forest resources, traditional forestrelated knowledge and livelihood of forest dependent communities: cases in South Korea. Forest Ecol. Manag. 257 (10), 2027-2034. https://doi.org/10.1016 /j.foreco.2009.01.054

Publisher's note Springer Nature remains neutral with regard to jurisdictional claims in published maps and institutional affiliations. 